that it is precisely in these cases of secret or concealed homicide that the medical examiner may render the greatest service to the community.

A prejudice in favor of an individual, or what is called "popularity," may screen a cuuning criminal, as, on the other hand, malevolence may bring suspicion upon the innocent; indeed in cases of sudden or unexpected death it is not safe to leave the question of the cause to the decision of the family, the police, the board of health, nor even of the doctor. There is a distinct advantage in an inquiry of this kind in calling upon a stranger, as it were an indifferent spectator, to whom all the facts are submitted anew, who can view the case from a new standpoint, whose sympathies and interests are in no way involved, and who, moreover, by special training and experience is competeut to decide upon the testimony.

It is claimed that the law has worked well. How can that be shown when, on the one hand, we have no means of knowing how many cases of secret homicide may have escaped detection under the guise of death from natural causes; nor, on the other, how often a groundless suspicion may remain in the minds of the community against an innocent person?

It is to be regretted that no statutory provision exists authorizing the medical examiner to make postmortems at his discretion in cases of unexplained death.

Both the State and the medical examiner would be the gainers by such legislation. In case a secret homicide should be revealed in this manner, the value of the law in its widest possible interpretation would be proved, while the medical examiner would have no difficulty in recovering payment for his labor; whereas if, as no doubt would happen most frequently, no crime was brought to light, not only might a cruel suspicion be removed from some innocent person, but much knowledge would be gained upon doubtful questions connected with sudden death, while mortuary statistics so far as they are based upon medical examiners' certificates would possess far greater value than now.

I would suggest that Section 10, of Chapter 26, of the Public Statutes might be amended acceptably as follows:

Medical examiners shall make a view of the dead bodies of such persons only as are supposed to have come to their death by violence; or, when called upon, when the death is sudden or the cause of death is unknown; in which case they are hereby authorized to make a post-mortem at their discretion, such post-mortem not to be returned as a medicolegal autopsy.

I append to my paper the following from a member of this Society :

August 23, 1894.

Dear Dr. Adams: - I am a little shy about trying my hand at tinkering statutes, and that is why I haven't replied sooner to your earlier request.

I am not thoroughly convinced that it is desirable to amend the law. While $I$ am in favor of the widest and most liberal latitude in the discretion under which medical examiners act, and while I believe (as I have always acted), that a medical examiner should not inquire closely into the character of the " notice" by which he is summoned, but should presume that in the mind of the one summoning him there is a good reason for the summons, I do think that the clause "such persons only as are supposed to have come to their death by violence" is a useful clause sometimes as a bar to frivolous calls and to calls clearly outside the function of the medical examiner, considered theoretically.
If I were commissioned to formulate statutory provisions which would conform closely to my own practice during the past seventeen years as a medical examiner, my suggestion would take this shape:

(1) Omit Section 10 of the present law altogether.

(2) Amend Section 11 by omitting the words "who is supposed to have come to his death by violence" and substitute therefor the words "into the cause and manner of whose death a medical inquiry is deemed necessary," so that the first part of the Section 11 would read: "When a medical examiner has notice that there bas been found, or is lying within his county, the dead body of a person into the cause and manner of whose death a medical inquiry is deemed necessary, he shall forthwith repair, etc."

'This change would sufficiently enlarge the medical examiner's jurisdiction to include all possible emergencies, without, in my belief, opening the door to abuse. It would take off the implied inhibition which now hampers some of our best examiners; and it would express what is really the practice of others of our leading men.

The only question in my mind is whether a change is either necessary or expedient. Personally, I am not hampered by the present statute, for I go whenever and wherever $I$ am called within my district, always assuming, in the absence of information to the contrary immediately available, that a medical inquiry into the cause and manner of the reported death is deemed necessary. And I feel sure that the same "discretion" in the way of executing this statute would be approved, whoever the examiner was. In this matter, I think Dr. Mead's position is correct, although a strict interpretation of the law is clearly against it ; but, on the other hand, if a strict interpretation of the law is insisted on, and every medical examiner before he answers a call, must run around the country hunting for that "supposition" of "violence" in the case, as a condition precedent to his official action, he and his law will become absurd. As I see things now, I don't very much care whether the door of opportunity for action under the statute is opened more widely, and I shall keep on answering calls, as I have done in the past, without a preliminary cross-examination of the motives of the person who does the act of calling me. In other words, I think we may say of the medical examiner, when he is summoned to a case :

His not to reason why ;
His not to make reply ;

His not to make reply;
His but to get there, spry

and take charge of the body.

Yours very truly,

\section{WAS IT MURDER OR SUICIDE? 1}

BY E. P. HURD, M.D., OF NEWBURYPORT, MASS., Medical Examiner, Third Essex District.

ON the morning of July 28, 1894, an empty boat was seen on the flats near Carr Island, opposite Jefferson Street, Newburyport. Its oars and anchor were missing. In the bottom of the boat, lying loose, were two boards which had served as seats. A straw hat, evidently the property of au adult man, was the only other thing which was found aboard. The boat was subsequently identified as the property of a resident of Amesbury who had left it at Black Rocks near the mouth of the Merrimac the day before. 'The oars and sail had been removed by him and locked up ashore. When the owner recovered his boat, he found, as before mentioned, that the anchor and about seven feet of rope were missing. On the morning of the $28 \mathrm{th}$ of July, as two fishermen of the South End were going to their clam-beds, they saw in shallow water, the tide

1 Read before the Massachusetts Medico-Legal Society, October ?, 1894. 
being low, the back of a man protruding above the surface of the water. This was at the edge of Hook's Chaunel, and the place where the body was discovered is nearly dry at low tide. They rowed up to the body, and found around its neck a rope about seven feet long attached to which was a boat anchor, weighing about nine pounds. The anchor was embedded in the mud, but had not caught. The body was lying with the face downward and had evidently been in the water several days, being badly swollen and discolored. The fishermen took the anchor into their boat and towed the body to one of the lower landings, where it was examined by me.

On the person of the dead man were two dime novels, which suggested an expectation of some leisure time, and papers which proved beyond doubt that he was C. F. A., of Haverhill, and also that he was a printer by trade. The body was that of a very large man, five feet ten inches high, weighing about 180 pounds. He was well dressed in a light-gray summer suit and a new pair of laced boots. No hat, no purse, no money, no watch, was on his person.

The remains were in a state of rapidly advancing putrefaction. The face was swollen and the features distorted. A frothy, sanious fluid ran from the mouth. The epidermis was livid, in spots green. The veins of the face and temples were engorged. The abdomen was enormously swollen (cadaveric tympanites); the thorax was livid, greenish, the epidermis in places peeling. A tight rope, with anchor attached, was around the neck; the knot was at the back part of the neck, and examination proved it to be a slip-noose. The knot seemed to be drawn very tight; there was a deep, wide crease around the neck where the rope had constricted the parts. Above and below this crease, the integument was swollen and overlapped. The knot seemed to me drawn tighter than any man could have drawn it himself with his hands above his head, pulling upwards; it was tight enough certainly to produce strangulation. I may say, however, that the deceased was a large muscular man, that a strong, nervous pull on the slip-noose thus adjusted would draw it pretty tight; and it is a perfectly defensible proposition that any strong man could thus inflict dangerous strangulation upon himself if he were disposed. It is the improbable that often happens.

There were no marks of violence on the person of the deceased other than those inflicted by the rope around his neck; no wounds, contusions, or fractures. A post-mortem examination subsequently made certainly favored the hypothesis of death by strangulation. There was no water in the lungs or stomach, nor in the pleural cavities. The right side of the heart was distended by dark blood; the left side was empty. The lungs were collapsed. Their bases were engorged with dark blood; the upper portions crepitated well on pressure. On section a frothy, sanious fluid exuded; the same fluid was fuund in the bronchi. There was intense lividity and swelling of the face, lips, hands, eyelids and scalp, with dark veins very prominent; the eyes were red and protruding, the tongue swollen and pro. truding. The mark of the rope around the neck, four days after the discovery of the body, was very pronounced. The brain, on account of the advanced decomposition, was not examined.

The epidermis of the feet and legs was of a livid, greenish color, and was macerated owing to long lying in the water. The blood was everywhere fluid, and was oozing in places, as on the thorax, owing to cracks in the skin.

The day of its discovery, the body was identified by the guardian and by a sister as belonging to C. F. A., of Haverhill, a young man twenty years of age, who had left home on the morning of the $19 \mathrm{th}$, and had not since been heard from. Careful examination revealed the fact that young $A$. was of dissipated habits. This opinion I had previously formed by a perusal of a diary found in his possession. He had kept very low company; had had intimate relations witb a certain disreputable female, and there was infatuation and deep jealousy. This fact I learned of the chief of police. For several days prior to his disappearance, he had acted strangely; had been moody, dejected, and had been heard to say that he wished himself dead. There had been a quarrel with his mistress.

A. never carried much money on his person; in fact, he was earning but moderate wages at his trade. There was no means of knowing how much money he had when he left home on the 18th or 19th of July, but the amount could not have been large. His guardian stated that $A$. had drawn on him the day before his disappearance for ten dollars. What became of the sum, the detective who undertook to work up the case was unable to determine. Certain it was, that there was no pocket-book and no money on A.'s person when found on the morning of the $28 \mathrm{th}$.

The owner of the boat found it on the morning of the 20th at Carr Island, as before stated. The rope and anchor found around the neck of $A$. were identified as belonging to the boat. The hat was A.'s hat. The boat had been anchored the day before at Black Rocks, near the mouth of the river. The sail and oars had been removed so that the boat might not be stolen.

We are now able to reconstruct a portion of this history. A. had wandered away from Haverbill on or about the 19th of July, and found himself at Black Rocks, a little retired landing, with about four houses a little distance from the water's edge. The presumption is that he came down in the electric-car. He was seen by no one on the way; no one remembers to have seen him from the time he left Haverhill till he arrived at Black Rocks. He was observed at Black Rocks on the evening of the 19 th by two rather suspicious characters, one of whom has served a short sentence in jail; this is according to the testimony of these parties, elicited by a detective. Yet these men deny having had any conversation with $A$. It was impossible to find a shred of evidence to connect either of them with the disappearance of A., though some hope was at first entertained by the detectives that a clue might be found here.

How did A. get to Hook's Channel where his body was found? That boat moored by its owner at the Black Rocks' landing, must bave borne the body of A. on the night of the 19 th to the place near Hook's Channel where it was found on the morning of the 28th. Did it bear him alive, or did it bear him a corpse? This is the question that is still unsolved.

One theory, entertained by many, is that $A$. was the victim of a foul murder. At Black Rocks he fell in with one or more desperadoes who, for money, or from some other motive, murdered him. He may have been lassoed, as the Thugs strangle their victims; he was then robbed of what little money he had. The 
murderers found that they had a corpse to get rid of ; there was only one boat there (as was the fact) and this boat was without oars. However, there was no other means of covering up their guilt; they hastily, under cover of the darkness, threw the body into the boat and paddled up the river with the seats of the boat (there were two of them) for oars. The tide was then setting strongly toward Newburyport; and if the boat had been left to the action of the tide alone, it would not have drifted out to where it was found, namels, at Hook's Channel. This is absolutely certain if we can rely on the testimony of all competent boatmen. Consequently, to reach Hook's Channel, the boat must have been paddled considerably out of the current. There was doubtless a good reason why the murderers of $\mathbf{A}$. (if this deed were really a homicide) preferred to row out of the main current - they would thus avoid any small boats which might be passing up or down the river. Hook's Channel was some distance to the left of the main current and boatmen would naturally keep away from that quarter, especially as it was shallow water in that direction. 'The theory then is that the supposed murderers, after paddling the boat with their dead body out to Hook's Channel, dumped the body overboard, first taking the precaution, by tying the anchor-rope about his neck with the anchor attached, that the body should never rise to the surface and tell of their crime. There is nothing inherently improbable in the supposition that this same rope was the instrument by which the murderous deed was accomplished in the first place. In favor of the theory of murder is the fact that the deceased when found had no knife in his possession with which the anchorrope could have been cut. Detective Hammond, however, makes light of this objection, for he has ascertained that $A$. was in the habit of carrying a pocket-knife with a large blade; this he might have flung into the river after cutting the rope. Another fact in favor of the murder theory is the absence of any money on the person of A. when found.

The subsequent course of our supposed murderers is easily imagined. They paddled their boats over to the Newburyport side, landing on Joppa Flats, then left it there and went their way unobserved and unsuspected. If they imagined that the place where they dumped their victim was deep water, subsequent developments revealed their mistake.

As for the boat, it might readily drift on the ascending tide from the place where it was left, to Carr Island, the other side of the river. This is conceded by the boatmen of Joppa and by others well acquainted with the river. On asking several of the river boatmen whether an empty boat which had been abandoned at Hook's Channel, where the dead body was found, would naturally float on the tide to Carr Island, I could not find one who believed that a boat would be likely to drift in that direction, but all admitted that the course of such a boat would depend somewhat on the wind. It does not seem to me improbable that a boat might drift with the tide from that locality to Carr island.

Against the homicide theory are (1) the want of any known motive for the murder; (2) the absence of any marks of violence on the person of the dead man other than those caused by the rope; (3) the absence of any clue to the murderer. Moreover, in favor of the suicide theory are the following considerations: (1) The testimony of A.'s employer and of his friends that he had been acting strangely, had been moody and taciturn; (2) that he seemed to have "skulked" away to Black Rocks (fifteen miles), not mingling with any company, and keeping his plans to himself; (3) the place where the Amesbury man's boat was left moored was a retired place - and a man who was meditating suicide would naturally seek such a place. In brief, we can easily imagine such a succession of events as these: In a state of melancholy, perhaps even of mental aberration, $\mathbf{A}$. strays to Black Rocks. He is meditating suicide, and finds the boat. The tide is flowing upward; he raises the anchor, and enters the boat. He is soon out in the midst of the current, drifting upward towards Newburyport. He shrinks from meeting other boats or being seen; he is determined to bury himself from all eyes and to do it so effectually that no one will ever know what has become of him. Especially is the thought gratifying to him that she who has caused him so many woes, whom he has so adored, but who has been false to him - that she will wonder what has become of him, will miss him, will perhaps some time long for him, but will never, never know his fate. The tide carries him towards Newburyport; he seizes the board on which he had been sitting and sculls to the left. 'There is a broad plain of ebbing waters in the direction of the clam-flats; it is quiet and retired out there; the water seems deep; bere is a good place to carry out the cherished design. Choosing what he thought a suitable place, he is about to cast himself overboard, when he remembers that he has heard that after a certain time bodies rise to the surface. This thought is abhorrent to him; he wishes to make his fate forever a mystery. He looks around for a weight; he sees the anchor, cuts the rope, throwing away the knife which he will never need again; he may have done the same thing by his pocketbook. It is the work of only a few moments to adjust the slip-noose to his neck; in his frenzy he gives a strong, impetuous tug with both hands on the rope, which, with the anchor, is now at arm's length above his head, and falls overboard. The anchor drags him to the bottom; the constriction of the gullet and windpipe by the rope precludes the entrance of water into the lungs and stomach, and fatal asphy xia soon sets in.

On the whole, I think the hypothesis of homicide the more probable. My first impression when I saw that man on the wharf with the noose so tightly drawn around his neck - This must have been murder - will probably yet be verified, if the old adage, "Murder will out" be true. Had A. designed to commit suicide he would have been satisfied with attaching the anchor rather loosely to his person, the object being only to keep the body from rising. Then again, the postmortem findings certainly favored the hypothesis of death by strangulation rather than by drowning. And yet I am aware that persons have died from drowning without swallowing a drop of water, owing to sudden constriction and closure of the glottis. There are, I believe, no absolutely reliable pathognomonic signs of death from drowning.

Prolonged Treatment of Fecal Accomularion.- A writer in a medical journal describes a case in which a fecal accumulation was made to disappear by an injection of glycerine per annum. The number of annual injections required is not stated. 